\title{
Hepatitis $B$ and $C$ virus infections among patients with end stage renal disease in a low-resourced hemodialysis center in Vietnam: a cross-sectional study
}

\author{
Cuong Minh Duong ${ }^{1}$, Dariusz Piotr Olszyna ${ }^{2}$ and Mary-Louise McLaws ${ }^{1 *}$
}

\begin{abstract}
Background: Hemodialysis services in Vietnam are being decentralised outside of tertiary hospitals. To identify the challenges to infection control standards for the prevention of bloodborne infections including hepatitis B virus ( $\mathrm{HBV}$ ) and hepatitis C virus (HCV) we tested the magnitude of HBV and HCV infections in the largest unit in Ho Chi Minh City servicing patients with end stage renal disease.

Methods: All 113 patients provided consent HBV surface antigen (HBsAg) and HCV core antigen (HCV-coreAg) testing. Positive patients were tested for viral genotypes. All participants completed a questionnaire on demographic characteristics, risk factors and previous attendance to other hemodialysis units.

Results: Seroprevalence of 113 patients enrolled was 7\% (8/113, 95\% Cl 2.3\%-11.8\%) HBsAg, 6\% (7/113, 95\% Cl 1.7\%-10.6\%) HCV-coreAg and 1\% (1/113, 95\% Cl 0.8\%-2.6\%) co-infection. Having a HBV positive sexual partner significantly increased the risk of acquiring HBV $(P=0.016$, Odds Ratio $(O R)=29,95 \% \mathrm{Cl} 2-365)$. Risk factors for HCV included blood transfusion $(P=0.049)$, multiple visits to different hemodialysis units $(P=0.048, O R=5.7,95 \% \mathrm{Cl}$ 1.2-27.5), frequency of hemodialysis $(P=0.029)$ and $A S T$ plasma levels $>40 \mathrm{IU} / \mathrm{L}(P=0.020, \mathrm{OR}=19.8,95 \% \mathrm{Cl}$ 2.3-171). On multivariate analysis only blood transfusion remained significant risk factor for HCV $(P=0.027$, adjusted $\mathrm{OR}=1.2$ ).

Conclusions: HCV screening for HCV of blood products must improve to meet the infection prevention challenges of decentralizing hemodialysis services. The level of HCV and HBV in our hemodialysis unit is a warning that universal precautions will be the next challenge for decentralised hemodialysis services in Vietnam.
\end{abstract}

Keywords: Hepatitis B virus, Hepatitis C virus, Hemodialysis, End stage renal disease, Vietnam, Universal precautions

\section{Background}

Hemodialysis is routinely used as renal replacement therapy for end stage renal disease (ESRD) patients [1]. In 2012, 2.1 million patients worldwide were estimated to require hemodialysis and this number is expected to increase by $7 \%$ annually [2]. Chronic hemodialysis patients are at increased risk for both HCV and HBV infections associated with contaminated blood and blood product transfusion and exposure to contaminated hemodialysis

\footnotetext{
* Correspondence: m.mclaws@unsw.edu.au

${ }^{1}$ School of Public Health and Community Medicine, UNSW Medicine, UNSW Australia, Level 3 Samuels Building, Sydney, NSW 2052, Australia Full list of author information is available at the end of the article
}

equipment during treatment [3-6]. Like the community, chronic hemodialysis patients may also acquire HBV and $\mathrm{HCV}$ through other at-risk activities, such as unprotected sexual contact and injecting drug use $[7,8]$. Several infection prevention strategies that are effective in reducing the acquisition of bloodborne virus by patients in high resourced healthcare settings includes erythropoiesisstimulating agents which has reduced the need of blood transfusion, HBV vaccination and the adherence by hemodialysis services to specific hemodialysis infection control guidelines [9].

In 1983 Vietnam commenced its hemodialysis services at tertiary hospitals for ESRD patients [10]. In Vietnam 6

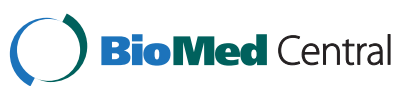

(C) 2015 Duong et al.; licensee BioMed Central. This is an Open Access article distributed under the terms of the Creative Commons Attribution License (http://creativecommons.org/licenses/by/4.0), which permits unrestricted use, distribution, and reproduction in any medium, provided the original work is properly credited. The Creative Commons Public Domain Dedication waiver (http://creativecommons.org/publicdomain/zero/1.0/) applies to the data made available in this article, unless otherwise stated. 
million, that is $6.73 \%$ of the general population, have been estimated to be diagnosed with chronic kidney disease [11]. Of these 6 million patients 80,000 (1.3\%) patients have already reached ESRD. Currently, the healthcare system in Vietnam can only provide treatment to $8,000(10 \%)$ of patients with ESRD. Further, 8,000 patients will be newly diagnosed annually of whom 104 (1.3\%) will also go onto require hemodialysis services of who 10 will receive hemodialyis [11]. To address the growing demand for hemodialysis, health services will be decentralised out of tertiary hospitals and become provincial services. Routine universal precautions and infection control practices for the prevention of bloodborne infections need to be established to protect the growing number of ESRD patients from further morbidity. Our study hemodialysis unit was the first decentralised district unit established in Ho Chi Minh City in Southern Vietnam in 2009. Since 2009 a further seven units now offer services to an average of 60-70 patients. We report our preliminary findings of the point seroprevalence, risk factors and genotype of HBV and HCV in newly admitted ESRD patients.

\section{Methods}

\section{Design of the study}

In the period between October 2012 and January 2013 all patients aged 18 years and older, newly admitted at the Hemodialysis Unit, District-6 Hospital, Ho Chi Minh City, Vietnam were enrolled to participate at the study. The study protocol was approved by the Human Research Ethics Committee at UNSW Australia (approval number HC12363), the Ho Chi Minh City Health Service and District-6 Hospital authorities.

Participants completed a self-administered questionnaire that comprised of demographics (age and sex), risk factors that included unprotected sexual contact, injecting drug use, barber use of razor blade shaving, piercings, tattooing, blood and blood product transfusions, and attendance to different hemodialysis units. Participants provided location, name of the hemodialysis unit and the year of admission so that the data for the number of different hemodialysis unit visits could be assessed as a risk factor. Assistance with the questionnaire was provided when needed by one investigator. Participants consented to HBV and HCV serology testing, viral genotyping. Aminotransaminases (AST and ALT), y-glutamyl transpeptidase (GGT), medical and dialysis information were obtained from patients' medical records. Dialysis information included: history of blood transfusion, surgery, abnormal liver function, duration (in months) of having hemodialysis services, frequency (in days) of hemodialysis treatments, number of different hemodialysis units admitted for hemodialysis services and dialyzer reuse.
To validate the information of self-reported transfusion history all medical records were reviewed for accuracy. Patients who reported a blood transfusion prior to admission to the unit were asked to provide the year, place of transfusion and the number of transfusion sessions.

HBV vaccination of new patients is currently not routinely practiced. Patients are encouraged to have HBV vaccination at their own cost. None of our patients is vaccinated. Financial constraint means it is common practice in Vietnam to reuse dialyzers. Used dialyzers are labeled with the patient's name. Used dialyzers for each patient, regardless of infection status, are cleaned and stored separately for reuse by the original identified patient. Given the unavailability of dedicated room for HBV or HCV infected persons, the study unit has designated machine for HCV or HBV infected patients. The unit plans weekly dialysis schedules according to patient availability and by infection status. Infected patients are always planned to receive their treatments at less crowded dialysis sessions. Patients are required to follow their dialysis schedules so they receive treatment at a given dedicated dialysis machine at a fixed time.

\section{Laboratory tests}

Serum samples obtained by centrifugation of blood samples at 3,000 g for 10 minutes were stored at $-20^{\circ} \mathrm{C}$ prior to testing. The ARCHITECT HCV Ag assay (ABBOTT Laboratories) which is a Chemiluminescent Microparticle Immunoassay (CMIA) was used to detect HCV-coreAg $[12,13]$. The ARCHITECT HBsAg assay (ABBOTT Laboratories), another CMIA, was used to detect the presence of HBsAg [14]. Positive samples using these assays were tested for HBV and HCV genotype by TRUGENE HBV Genotyping kit [15] and TRUGENE HCV 5'NC Genotyping kit (SIEMENS) [16,17] respectively. Immunoassays did not require sample processing. For HBV genotyping, DNA from serum samples extracted by MagNAPure LC instrument (Roche Diagnostics) was amplified before performing Crosslinking and immunoprecipitation (CLIP) sequencing to obtain the query sequence in accordance with the manufacturer's protocol. Genotype was identified by comparing the query sequence to the HBV genotype consensus sequences of the OpenGene system software. For HCV genotyping, a 244-base pair sequence in the 5'non-coding region of $\mathrm{HCV}$ RNA extracted by MagNAPure LC instrument (Roche Diagnostics) was amplified before performing bidirectional CLIP sequencing to obtain the sequencing products. These segments were then detected using the OpenGene DNA Sequencing System. The forward and reverse sequences were combined to form a query sequence. Genotype was identified by comparing the query sequence to the previously characterized isolates in the Trugene $\mathrm{HCV} 5^{\prime} \mathrm{NC}$ Molecule of the OpenGene system software. 


\section{Statistical analysis}

Data were managed and analysed using Statistical Package for the Social Sciences (SPSS) version 20 (IBM). Fisher's Exact test was used to analyse the significant relationships between categorical data and Mann-Whitney $U$ test was used for the comparison of continuous data. Correlations were used to test for the strength of association between continuous variables. A multinomial logistic regression (MLR) model was used to test risk factors for HCV seroconversion. Independent variables were entered into the model and included quantity of blood transfusion, number of different hemodialysis units admitted for treatment, the frequency of hemodialysis treatments, duration of hemodialysis, and AST >40 IU/L. A HBV seroconversion model to identify significant risk factors could not be built. Alpha was set at $5 \%$ level.

\section{Results}

\section{Predisposing factors}

113 participants attended the clinic during the 4 months of enrolment. The mean age of participants was 53 years (SD \pm 16 years, range $18-86$ years) (Table 1 ). Just over half (52\%) of the participants were female and most (98\%) reused dialyzers. The mean duration of hemodialysis was 36 months ( $\mathrm{SD} \pm 43$ months, range 1.8-245.5 months). The mean number of hemodialysis treatments was 391 ( $\mathrm{SD} \pm 489$, range 7-2946 events) and 99\% (112/ 113) were documented to have received treatment at other hemodialysis units. Over half $(65 \%, 73 / 113)$ of all patients had received a blood transfusion. Causes of ESRD included hypertension (31\%, 35/113), type-2 diabetes mellitus (30.1\%, 34/113), glomerulonephritis $(21.2 \%, 24 / 113)$, obstructive nephropathy plus interstitial

Table 1 Patient demographics and clinical characteristics

\begin{tabular}{ll}
\hline Female \% (n/N) & $52(59 / 113)$ \\
Age (years) & $54[40 ; 64]$ \\
Median [LQ; UQ] & $(53 \pm 16)$ \\
(Mean $\pm \mathrm{SD})$ & $18-86$ \\
Range & \\
Duration of hemodialysis (months) & $18[10 ; 38]$ \\
Median [LQ; UQ] & $(36 \pm 43)$ \\
(Mean $\pm \mathrm{SD})$ & $1.8-245.5$ \\
Range & \\
Frequency of hemodialysis treatments (days) & $195[87 ; 441]$ \\
Median [LQ; UQ] & $(391 \pm 489)$ \\
(Mean $\pm S D)$ & $7-2946$ \\
Range & $98(111 / 113)$ \\
Patients reusing dialyzer \% (n/N) & $65(73 / 113)$ \\
Patients previously having blood transfusion \% (n/N) & $99(112 / 113)$ \\
Patients having different hemodialysis unit visits \% (n/N)
\end{tabular}

kidney disease $(3.5 \%, 4 / 113)$ and unknown cause $(2.7 \%$, 3/113) (Figure 1).

\section{Seroprevalence and genotyping}

Most patients (86\%, 95\% CI 79.4\%-92.2\%, 97/113) were negative for both HBsAg and HCV-coreAg, 7\% (95\% CI $2.3 \%-11.8 \%, 8 / 113)$ were HBsAg positive, $6 \%$ (95\% CI $1.7 \%-10.6 \%, 7 / 113)$ were $\mathrm{HCV}$-coreAg positive and $1 \%$ (95\% CI 0.8\%-2.6\%,1/113) was HBsAg and HCV-coreAg positive. The viral genotype distribution among patients who were $\mathrm{HCV}$-coreAg positive was $1 \mathrm{~b}$ (3 patients), 1a ( 2 patients) and 6a (1 patient) and 2 patients who were $\mathrm{HCV}$-coreAg positive with untypable virus. There were 5 patients with HBV genotype $B$ and 4 patients who were $\mathrm{HBsAg}$ positive with untypable virus.

\section{Risk factors for HCV infection}

Five risk factors (unprotected sexual contact, injecting drug use, barber use of razor blade shaving, piercings and tattooing) were not significantly associated with HBV or $\mathrm{HCV}$.

None of the HCV positive patients reported to have HCV-positive sexual partner (Table 2). Patients who were $\mathrm{HCV}$ positive were significantly more likely have received at least one blood transfusion $(\mathrm{P}=0.049)$ and significantly more likely ( $\mathrm{P}=0.048$, OR $5.7,95 \%$ CI $1.2-27.5$ ) to have visited more than two different hemodialysis units compared with $\mathrm{HCV}$ negative patients. The amount of blood unit transfused was found to be significantly correlated with duration of hemodialysis $(\mathrm{r}=0.33, \mathrm{p}<0.01)$. $\mathrm{HCV}$ positive patients had significantly more hemodialysis treatments than $\mathrm{HCV}$ negative patients (949 vs 348 , $\mathrm{P}=0.029$ ) (Table 3 ). The duration of hemodialysis was not a significant risk factor $(\mathrm{P}=0.068)$.

\section{Risk factors for HBV infection}

Patients with HBV positive sexual partners were significantly more likely $(\mathrm{P}=0.016$, OR $29.0,95 \%$ CI 2.0 365.0) to be $\mathrm{HBV}$ positive compared HBV negative patients (Table 2). Visiting more than two different hemodialysis units $(\mathrm{P}=1.0)$, duration of hemodialysis treatment $(\mathrm{P}=0.351) \quad$ (Table 3$)$ and the frequency of hemodialysis treatments $(\mathrm{P}=0.284)$ were not a risk factor for HBV infection.

\section{Association between AST, ALT and GGT and HBV and HCV infections}

After removing potential risk factors (cirrhosis, alcohol and herbal consumption) that can increase liver enzyme, ALT, AST and GGT $>40 \mathrm{IU} / \mathrm{L}$ were observed in $3 \%$ (3/113), 4\% (4/113) and 23\% (25/113) of study participants respectively. AST $>40$ was associated with $\mathrm{HCV}$ positivity $(\mathrm{P}=0.02$, OR $19.8,95 \% \mathrm{CI} 2.3-171)$ while ALT $>40(\mathrm{P}=0.18)$ and GGT $>40(\mathrm{P}=0.35)$ were not. 


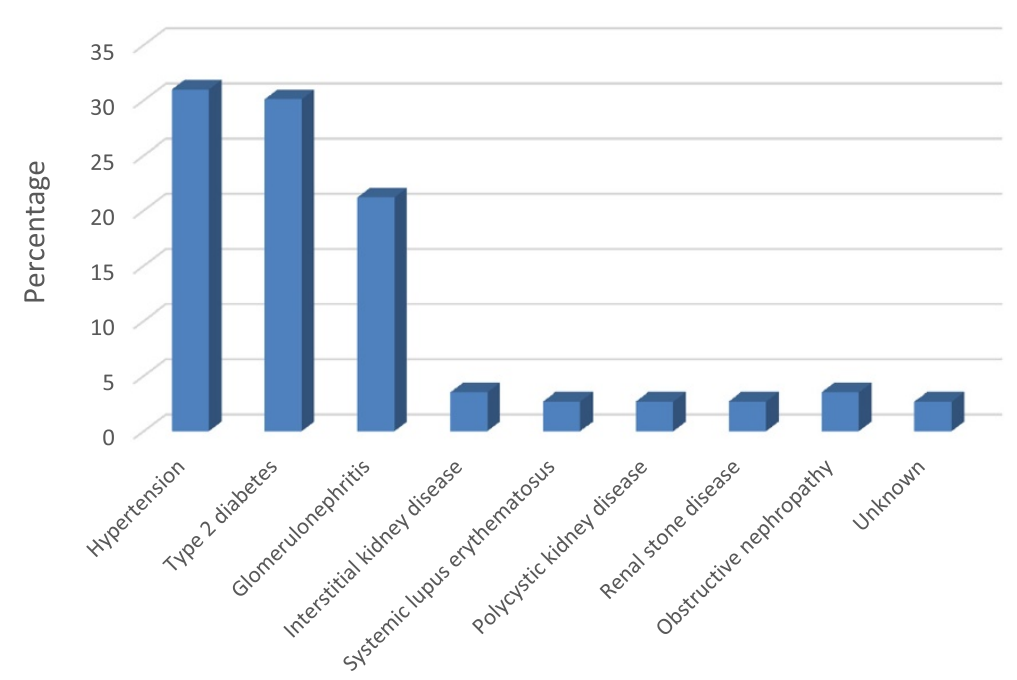

Figure 1 Etiologies of end stage renal disease on admission.

AST, ALT and GGT $>40$ were not associated with HBV positivity $(\mathrm{P}>0.05)$.

\section{Model for the prediction of seroconversion}

No other predictor for HCV seroconversion was identified other than the number of blood transfusion (AOR 1.16, 95\% CI 1.01-1.33, P = 0.027) (Table 4).

\section{Discussion}

The seroprevalence in hemodialysis patients in Western countries ranges from $5 \%-10 \%$ for $\mathrm{HCV}$ and $0 \%-6.6 \%$ for HBV $[9,18]$. The seroprevalence rates in our patients were similar at $6 \%$ for $\mathrm{HCV}$ and $7 \%$ for $\mathrm{HBV}$. Anti-HCV and HBsAg assays are the usual method for screening blood donors in Southern Vietnam where our study was conducted. The HCV screening rate in Southern Vietnam blood donors is reported at $0.8 \%, 7.5$ times smaller than the rate in our patients and the HBV screening rate in donors, $3.7 \%$, is also less than the rate we found in our patients [19]. The implementation of infection control precautions were issued in 1997 in Vietnam [20]. However, prior to 2001, the prevalence rates for HCV among chronic hemodialysis patients in tertiary hospitals in Ho
Chi Minh City and Hanoi, Vietnam, were hyperendemic at $44 \%$ to $57 \%$ respectively [21,22]. Gradually awareness of infection control measures for blood transfusion safety increased and screening all blood products for bloodborne viruses commenced in 2001 [23]. In 2009 the prevalence of $\mathrm{HCV}$ in hemodialysis patients from 5 major cities across Vietnam had reduced but remained hyper-endemic at $26.6 \%$ [24]. A six-year cohort study, from 2006 to 2011, in one hemodialysis unit in Ho Chi Minh City the HCV prevalence of $19.6 \%$ (95\% CI $12.4 \%-15.2 \%$ ) was three times higher than the prevalence in our hemodialysis patient population [25]. Longterm hemodialysis patients may induce false-negative results as a result of an unstable immune response in up to $17.9 \%$ of patients tested [26]. We believe the false negative results in our study will have been negligible as the specificity of HCV-coreAg assay was $99.8 \%$ and the sensitivity of the assay is equivalent to HCV-RNA assay [12]. The prevalence for $\mathrm{HBV}$ at $4.9 \%$ (95\% CI $2.2 \%-$ 7.2\%) [25] and co-infection of $\mathrm{HCV}$ and $\mathrm{HBV}$ at $2.1 \%$ (95\% CI 1.0\%-3.3\%) [25] from the cohort study were similar to the rates in our population. Currently, universal precautions are applied in Vietnam. Yet, our findings

Table 2 Unadjusted risk factors tested for hepatitis $C$ and hepatitis B infections

\begin{tabular}{|c|c|c|c|c|c|c|}
\hline \multirow[t]{2}{*}{ Risk factors } & \multicolumn{3}{|l|}{ HCV \% (N) } & \multicolumn{3}{|l|}{ HBV \% (N) } \\
\hline & Positive (8) & Negative (105) & $P^{a}$ & Positive (9) & Negative (104) & $P^{a}$ \\
\hline HBV-positive sexual partners & 0 & $2.8(3)$ & undetermined OR 1.0 & $22.2(2)$ & $1(1)$ & $29(2-365) 0.016$ \\
\hline HCV-positive sexual partners & 0 & $1.0(1)$ & undetermined OR 1.0 & $11.1(1)$ & 0 & undetermined OR 0.08 \\
\hline At least one blood transfusion & $100(8)$ & $61.9(65)$ & undetermined OR 0.049 & $77.8(7)$ & $63.5(66)$ & $2.0(0.4-10.2) 0.5$ \\
\hline $\begin{array}{l}\text { Having }>2 \text { different hemodialysis } \\
\text { unit visits }\end{array}$ & $37.5(3)$ & $9.5(10)$ & $5.7(1.2-27.5) 0.048$ & $11.1(1)$ & $11.5(12)$ & $1.0(0.1-8.3) 1.0$ \\
\hline
\end{tabular}

aisher's Exact Test. 
Table 3 Association between hemodialysis treatment and HCV and HBV infections

\begin{tabular}{|c|c|c|c|c|c|c|}
\hline \multirow[t]{2}{*}{ Risk factor } & \multicolumn{3}{|l|}{$\mathrm{HCV}($ mean $\pm \mathrm{SD})$} & \multicolumn{3}{|l|}{$\mathrm{HBV}($ mean $\pm \mathrm{SD})$} \\
\hline & Positive $(\mathrm{N}=8)$ & Negative $(\mathrm{N}=105)$ & $P^{b}$ & Positive $(\mathrm{N}=9)$ & Negative $(N=104)$ & $P^{b}$ \\
\hline Frequency of hemodialysis treatments (days) & $949.4 \pm 998.5$ & $348 \pm 405.5$ & 0.029 & $366.1 \pm 251.9$ & $392.7 \pm 504.9$ & 0.284 \\
\hline Duration of hemodialysis (months) & $80.1 \pm 82.6$ & $32.6 \pm 37.2$ & 0.068 & $32 \pm 20$ & $36.3 \pm 44.6$ & 0.351 \\
\hline
\end{tabular}

${ }^{\mathrm{b} M a n n-W h i t n e y} U$ test.

suggest universal precaution guidelines have yet to become routine practice. In addition, seven of our eight $\mathrm{HCV}$ positive patients were transfused after 2001. The hyper-endemic HCV and HBV in our hemodialysis patients suggests that poorly screened blood products are likely to be the source of infection. Besides, age at the time of acquiring HBV infection is strongly associated with population endemicity [27]. Vietnam is a high HBV endemic area $[28,29]$ with perinatal and horizontal routes still responsible for the majority of transmission [27].The rate of HBV in our patient population was similar to other hemodialysis patients in Vietnam several years earlier [25] suggesting the risk is stable possibly due to the high level of community infection acquired early in life. Hemodialysis patients in Vietnam would benefit from HBV vaccination prior commencing hemodialysis treatment.

Blood transfusion is an important risk for $\mathrm{HCV}$ infection among maintenance hemodialysis patients [18]. Our $\mathrm{HCV}$ positive patients were more likely to have acquired infection from multiple clinics and receiving more than two blood transfusions. The quality and type of diagnostic test used will impact on the false negative rates making comparisons of prevalence infection prevention strategies between countries and in-country units inaccurate. The duration of the window period, the time between the onset of $\mathrm{HCV}$ infection and first detection of antibodies/antigens in the bloodstream, varies with the most commonly used generation of serology test from 66 days to only 4 days with the nucleic acid test (NAT) [30]. The NAT test has greater sensitivity for detecting HCV. Several high resourced countries since 1997 have used NAT as the routine screening test for blood donors [31]. By 2015 major cities in Vietnam will

Table 4 Multinominal logistic regression analysis for predictors of HCV infections

\begin{tabular}{lll}
\hline Risk factors & $\mathbf{P}$ & Adjusted OR (95\% CI) \\
\hline $\begin{array}{l}\text { Number of transfused blood (unit) } \\
\text { Number of different hemodialysis }\end{array}$ & 0.027 & $1.16(1.01-1.33)$ \\
$\begin{array}{l}\text { unit visited } \\
\text { Frequency of hemodialysis }\end{array}$ & 0.33 & $1.70(0.57-5.05)$ \\
treatments (days) & & \\
$\begin{array}{l}\text { Duration of hemodialysis (months) } \\
\text { AST }>40(I U / L)\end{array}$ & 0.36 & $0.93(0.74-1.17)$ \\
\hline
\end{tabular}

use NAT as the screening test for blood donations [32]. We found a modest but significant linear relationship between blood transfusions and prolonged hemodialysis treatment $(\mathrm{r}=0.33, \mathrm{p}<0.01)$. The decision to transfuse ESRD patients with anemia is dependent on several indicators, the patient's age, presence of cardiovascular diseases and severity of anemia symptoms [33]. A third of our patients were $\geq 60$ of age, $43 \%$ had cardiovascular diseases and a quarter had chronic blood loss due to gastrointestinal diseases. These indications support repeated blood transfusion and the use of erythropoiesisstimulating agents. However, one unit of blood transfusion increased the odds for HCV in our patients by 1.16 times. Yet, by strictly complying with a treatment plan, patients can reduce the risk of anemia that requires blood transfusions and possible HCV infection. Time on hemodialysis was not a risk factor for $\mathrm{HCV}$ infection in our study though it was reported elsewhere $[18,34]$. This can be explained by the fact that it may not reflect the true duration of exposure to hemodialysis. Financial constraints often prevent patients in Vietnam from following their treatment plan. The risk associated with the frequency of hemodialysis treatments and $\mathrm{HCV}$ could therefore be a proxy for duration.

Challenges for patients having multiple hemodialysis treatments include repeated vascular access [6] and potential for exposure to contaminated venous access devices due to breaches in infection control precautions [35]. Increased risk for $\mathrm{HCV}$ was associated with visits to multiple hemodialysis units in our study and elsewhere [36] which suggests differences in infection control precautions occur between units. In Vietnam, arteriovenous fistula (FAV) operation is not routinely performed outside a tertiary urban unit. Patients from smaller units found outside the larger cities, are currently referred to tertiary units for FAV operation. During their admission for FAV the patient will receive hemodialysis. Nearly all our patients had visited at least two other hemodialysis units. Smaller units may one day provide FAV surgery to reduce the cost and inconvenience to patients who are forced to be referred to units in the city. But the practice of universal precautions will need to be routinely applied to prevent surgery-associated infections.

$\mathrm{HCV}$ genotypes and subtypes are geographically diverse $[37,38]$. In Vietnam, type $1 \mathrm{~b}$ and $6 \mathrm{a}$ are the predominant genotypes $[39,40]$. Among the typable infections in our 
patients, $\mathrm{HCV}$ genotype 1b was predominant followed by 1a and 6a. Sixty-four chronic hemodialysis HCV infected patients from Northern Vietnam in 2008 were found to have a similar genotype distribution with predominance of genotype 1 [41]. But the real-time RT-PCR technique used in this study prevented the HCV subtype from being identified. Among the typable HBV infections, the most common genotype was $B$ concurring with reports from other patient sources in Vietnam [42,43].

Increased transaminase levels are associated with $\mathrm{HCV}$ infection [44]. However, elevation of transaminases ( $>40 \mathrm{IU} / \mathrm{L}$ ) is not always present in chronic hemodialysis patients with viral hepatitis [45]. We found that AST $>40$ was significantly associated with HCV infection. This suggests that an unexplained or slight increase in AST could be used to signal early HCV seroconversion. We did not find an association between increased transaminases and HBV infection.

\section{Conclusions}

The challenge for Vietnam as it rolls out hemodialysis units from teaching hospitals into smaller centers will be the faultless routine application of universal precautions, early HBV vaccination and stringent screening of blood products countrywide.

\section{Abbreviations}

ALT: Alanine aminotransferase; AST: Aspartate aminotransferase; FAV: Arteriovenous fistula; CMIA: Chemiluminescent microparticle immunoassay; ESRD: End stage renal disease; GGT: y-glutamyl transpeptidase; HBV: Hepatitis B virus; HCV: Hepatitis C virus; HBsAg: Hepatitis B virus surface antigen; HCV-coreAg: Hepatitis C virus core antigen; NAT: Nucleic acid test; OR: Odds ratio; UNSW: University of New South Wales.

\section{Competing interests}

The authors declare that they have no competing interests.

\section{Authors' contributions}

CMD, DPO and MLM designed the study and drafted the manuscript. MLM supervised CMD who performed data collection and statistical analysis. All authors read and approved the final manuscript.

\section{Acknowledgements \\ We are grateful to our collaborators Drs Nguyen Thi Kim Phuong, Ngo Thanh Dieu, Pham Kieu Nguyet Oanh, Duong Bich Thuy and Bui Ngoc Minh Tam for data assistance; Pharmacist Nguyen Thanh Tong and Dr Nguyen Bao Toan for laboratory support; Drs Nguyen Trong Khoa and Nguyen Trieu Van for providing updates on the local epidemiology; and Associate Professor Nguyen Duy Phong for assistance with securing the research clinic site.}

\footnotetext{
Author details

${ }^{1}$ School of Public Health and Community Medicine, UNSW Medicine, UNSW Australia, Level 3 Samuels Building, Sydney, NSW 2052, Australia. ${ }^{2}$ Division of Infectious Diseases, University Medicine Cluster, National University Health System, Singapore, Singapore.
}

Received: 3 October 2014 Accepted: 13 February 2015

Published online: 27 February 2015

\section{References}

1. Fleming GM. Renal replacement therapy review: past, present and future. Organogenesis. 2011;7:11.
2. Fresenius Medical Care, editor. ESRD patients in 2012: a global perspective. Bad Homburg: Fresenius Medical Care AG \& Co. KGaA, Hof a.d. Saale; 2012.

3. WHO. Global surveillance and control of hepatitis C. J Viral Hepat. 1999;6:35-47.

4. CDC. Recommendations for prevention and control of hepatitis $C$ virus (HCV) infection and HCV-related chronic disease. MMWR Recomm Rep. 1998;47:1-39.

5. Lavanchy D. The global burden of hepatitis C. Liver Int. 2009;29 Suppl 1:74-81.

6. Cendoroglo Neto M, Draibe SA, Silva AE, Ferraz ML, Granato C, Pereira CA, et al. Incidence of and risk factors for hepatitis $B$ virus and hepatitis $C$ virus infection among haemodialysis and CAPD patients: evidence for environmental transmission. Nephrol Dial Transplant. 1995;10:240-6.

7. Hahn JA. Sex, drugs, and hepatitis C virus. J Infect Dis. 2007;195:1556-9.

8. Shepard CW, Simard EP, Finelli L, Fiore AE, Bell BP. Hepatitis B virus infection: epidemiology and vaccination. Epidemiol Rev. 2006;28:112-25.

9. Edey M, Barraclough K, Johnson DW. Review article: Hepatitis B and dialysis. Nephrology. 2010;15:137-45.

10. Bui PV. Dialysis in Vietnam. Perit Dial Int. 2007;27:400-4.

11. Approximately 6 million Vietnamese people have chronic kidney disease [in Vietnamese] [http://www.quangninh.gov.vn/vi-vn/so/soyte/Trang/Tin\% 20chi\%20ti\%E1\%BA\%BFt.aspx?newsid=39\&dt=2009-04-06\&cid=3]

12. Morota K, Fujinami R, Kinukawa H, Machida T, Ohno K, Saegusa H, et al. A new sensitive and automated chemiluminescent microparticle immunoassay for quantitative determination of hepatitis $C$ virus core antigen. J Virol Methods. 2009;157:8-14.

13. Li Cavoli G, Zagarrigo C, Schillaci O, Servillo F, Tralongo A, Coglitore M, et al. Hepatitis $C$ virus core antigen test in monitoring of dialysis patients. Hepatitis Res Treat. 2012;2012:4.

14. Cabezas-Fernandez MT, Cabeza-Barrera MI. Introduction of an automated system for the diagnosis and quantification of hepatitis B and hepatitis $C$ viruses. Open Virol J. 2012;6:122-34.

15. Tuaillon E, Mondain A-M, Nagot N, Ottomani L, Kania D, Nogue E, et al. Comparison of Serum HBsAg Quantitation by Four Immunoassays, and Relationships of HBsAg Level with HBV Replication and HBV Genotypes. PLoS One. 2012;7:e32143.

16. Nolte FS, Green AM, Fiebelkorn KR, Caliendo AM, Sturchio C, Grunwald A, et al. Clinical evaluation of two methods for genotyping hepatitis $C$ virus based on analysis of the $5^{\prime}$ noncoding region. J Clin Microbiol. 2003;41:1558-64

17. Chevaliez S, Pawlotsky JM. Hepatitis C virus: virology, diagnosis and management of antiviral therapy. World J Gastroenterol. 2007;13:2461-6.

18. Fabrizi F. Hepatitis C virus infection and dialysis: 2012 update. ISRN Nephrol. 2013;2013:11.

19. Pham TD. Current donated blood screening status of some blood-borne pathogens. [in Vietnamese]. In: Orientation on viral hepatitis prevention and control in Vietnam. Hanoi: Vietnam Ministry of Health; 2012.

20. Do NP. Decision on promulgation of the hospital regulation. [in Vietnamese]. Hanoi: Vietnam Ministry of Health; 1997.

21. Phan BL, Tran VB, Pham HP. The problem of HCV infection at Cho Ray hospital [in Vietnamese]. Tap Chi Y Hoc Viet Nam. 1995;9:27-31.

22. Bui TMA, Do TP, Nguyen $Y L$, Nguyen TV, Nguyen CT, Do MT, et al. HCV infection among haemodialysis patients and some subjects who have relationship with blood transfusion in Vietnam [in Vietnamese]. Tap Chi Y Hoc Viet Nam. 1999;1:13-8.

23. Do TP. Result of the national HIV, HCV, HBV screening program for the blood donors from 1996 to 2000 [in Vietnamese]. Tap Chi Y Hoc Viet Nam. 2001:12:5-8.

24. Dunford L, Carr MJ, Dean J, Waters A, Nguyen LT, Ta Thi TH, et al. Hepatitis $C$ virus in Vietnam: high prevalence of infection in dialysis and multi-transfused patients involving diverse and novel virus variants. PLoS One. 2012;7:e41266.

25. Nguyen B, Nguyen VT, Bui VT, Le NT, Bui TH, Tran HND. Epidemiology of hepatitis $B$ and $C$ virus infection in chronic hemodialysis: a study during 6 years. [in Vietnamese]. Y Hoc Thanh Pho Ho Chi Minh. 2012;16:77-83.

26. El-Sherif A, Elbahrawy A, Aboelfotoh A, Abdelkarim M, Saied Mohammad AG, Abdallah AM, et al. High false-negative rate of anti-HCV among Egyptian patients on regular hemodialysis. Hemodial Int. 2012;16:420-7.

27. Hou J, Liu Z, Gu F. Epidemiology and Prevention of Hepatitis B Virus Infection. Int J Med Sci. 2005;2:50-7.

28. Nguyen VTT, Law MG, Dore GJ. An enormous hepatitis B virus-related liver disease burden projected in Vietnam by 2025. Liver Int. 2008;28:525-31. 
29. Nguyen VT, McLaws ML, Dore GJ. Highly endemic hepatitis B infection in rural Vietnam. J Gastroenterol Hepatol. 2007;22:2093-100.

30. Marwaha N, Sachdev S. Current testing strategies for hepatitis C virus infection in blood donors and the way forward. World J Gastroenterol. 2014;20:2948-54

31. Roth WK, Busch MP, Schuller A, Ismay S, Cheng A, Seed CR, et al, International survey on NAT testing of blood donations: expanding implementation and yield from 1999 to 2009. Vox Sang. 2012;102:82-90.

32. Nguyen TX. Circular of information for the blood transfusion activities [decision, in Vietnamese]. Hanoi: Vietnam Ministry of Health; 2013.

33. Macdougall IC, Obrador GT. How important is transfusion avoidance in 2013? Nephrol Dial Transplant. 2013;28:1092-9.

34. Fissell RB, Bragg-Gresham JL, Woods JD, Jadoul M, Gillespie B, Hedderwick SA, et al. Patterns of hepatitis $C$ prevalence and seroconversion in hemodialysis units from three continents: the DOPPS. Kidney Int. 2004;65:2335-42

35. Savey A, Simon F, Izopet J, Lepoutre A, Fabry J, Desenclos JC. A large nosocomial outbreak of hepatitis $C$ virus infections at a hemodialysis center. Infect Control Hosp Epidemiol. 2005;26:752-60.

36. Carneiro MA, Teles SA, Dias MA, Ferreira RC, Naghettine AV, Silva SA, et al. Decline of hepatitis C infection in hemodialysis patients in Central Brazil: a ten years of surveillance. Mem Inst Oswaldo Cruz. 2005;100:345-9.

37. Te HS, Jensen DM. Epidemiology of hepatitis B and C viruses: a global overview. Clin Liver Dis. 2010;14:1-21.

38. Chao DT, Abe K, Nguyen MH. Systematic review: epidemiology of hepatitis $C$ genotype 6 and its management. Aliment Pharmacol Ther 2011;34:286-96.

39. Ho TD, Pham TTT, Nguyen TT, Nguyen BT, Phan HBH, Nguyen BT, et al. Prevalence of HCV genotypes in Vietnam [in Vietnamese]. Y Hoc Thanh Pho Ho Chi Minh. 2006;10:28-34.

40. Nguyen TB, Pham HV. Apply the direct sequencing of the QPCR products [in Vietnamese]. Y Hoc Thanh Pho Ho Chi Minh. 2009;13:243-8.

41. Truong TP. Characteristics of HCV infection among haemodialysis patients at Bach Mai hospital [Master dissertation, in Vietnamese]. Hanoi: Hanoi Medical University, Microbiology Department; 2008.

42. Bui HH, Dinh DLH, Pham HP, Sablon E. Hepatitis B genotypes in patients with cirrhosis and hepatocellular carcinoma [in Vietnamese]. Y Hoc Thanh Pho Ho Chi Minh. 2003;7:128-33.

43. Dang MAT, Vo DXA, Pham HV. Surveillance of the mutations responsible for Adefovir and Lamivudine resistance on the HBV extracted from patients' sera with chronic hepatitis B. [in Vietnamese]. Y Hoc Thanh Pho Ho Chi Minh. 2010;14:287-93.

44. Jasuja S, Gupta AK, Choudhry R, Kher V, Aggarwal DK, Mishra A, et al. Prevalence and associations of hepatitis C viremia in hemodialysis patients at a tertiary care hospital. Indian J Nephrol. 2009;19:62-7.

45. Yasuda K, Okuda K, Endo N, Ishiwatari Y, Ikeda R, Hayashi H, et al. Hypoaminotransferasemia in patients undergoing long-term hemodialysis: clinical and biochemical appraisal. Gastroenterology. 1995;109:1295-300.

\section{Submit your next manuscript to BioMed Central and take full advantage of:}

- Convenient online submission

- Thorough peer review

- No space constraints or color figure charges

- Immediate publication on acceptance

- Inclusion in PubMed, CAS, Scopus and Google Scholar

- Research which is freely available for redistribution 